\title{
The value of indirect measures for assessing food preferences in abnormal eating
}

Citation for published version (APA):

Roefs, A. J., Werrij, M. Q., Smulders, F. T. Y., \& Jansen, A. T. M. (2006). The value of indirect measures for assessing food preferences in abnormal eating. Journal für Verbraucherschutz und Lebensmittelsicherheit-Journal of Consumer Protection and Food Safety, 1, 180-186. https://doi.org/10.1007/s00003-006-0034-1

Document status and date:

Published: 01/01/2006

DOI:

10.1007/s00003-006-0034-1

Document Version:

Publisher's PDF, also known as Version of record

Document license:

Taverne

Please check the document version of this publication:

- A submitted manuscript is the version of the article upon submission and before peer-review. There can be important differences between the submitted version and the official published version of record.

People interested in the research are advised to contact the author for the final version of the publication, or visit the DOI to the publisher's website.

- The final author version and the galley proof are versions of the publication after peer review.

- The final published version features the final layout of the paper including the volume, issue and page numbers.

Link to publication

\footnotetext{
General rights rights.

- You may freely distribute the URL identifying the publication in the public portal. please follow below link for the End User Agreement:

www.umlib.nl/taverne-license

Take down policy

If you believe that this document breaches copyright please contact us at:

repository@maastrichtuniversity.nl

providing details and we will investigate your claim.
}

Copyright and moral rights for the publications made accessible in the public portal are retained by the authors and/or other copyright owners and it is a condition of accessing publications that users recognise and abide by the legal requirements associated with these

- Users may download and print one copy of any publication from the public portal for the purpose of private study or research.

- You may not further distribute the material or use it for any profit-making activity or commercial gain

If the publication is distributed under the terms of Article $25 \mathrm{fa}$ of the Dutch Copyright Act, indicated by the "Taverne" license above, 


\title{
The Value of Indirect Measures for Assessing Food Preferences in Abnormal Eating
}

\author{
A. Roefs, M. Q. Werrij, F. T. Y. Smulders, and A. Jansen \\ Maastricht University, The Netherlands \\ Correspondence to: Anne Roefs, Maastricht University, Faculty of Psychology (UNS 40), Experimental Psychology, P.O. Box 616, \\ 6200 MD Maastricht, The Netherlands, Tel.: +3143 3882191, Fax: +3143 3884196, E-mail: a.roefs@psychology.unimaas.nl
}

Received: September 12, 2005; Accepted: September 23, 2005

Key words: Food preference, abnormal eating

Abstract: Indirect measures have been used for the assessment of food preferences. These measures are indirect in the sense that the researcher does not ask a participant directly for his food preference, but derives his preference from a behavior. Typically, the affective priming paradigm and the Implicit Association Test have been used. The relevant processes in these paradigms are relatively automatic. One of the advantages of these paradigms is that responses are less likely to be influenced by socially desirable response tendencies and do not rely on the participant's introspection. This paper provides an overview of research about relatively automatic associations with food in general and specifically for anorexia nervosa patients, dieters, and obese people. Multiple studies suggest that these paradigms can uncover food likes and dislikes. In most studies, no differences in food preferences were found between obese and lean people, or between restrained and unrestrained eaters. Possibly there simply are no group differences in automatic food associations. Alternatively, the employed indirect measures are not sensitive enough to detect truly existent differences. Interestingly, it was found that anorexia nervosa patients displayed a reduced sensitivity to the palatability of foods. Another interesting finding is that the presence of an immediate food related context influenced the automatic food associations. For now, the use of indirect measures in explaining differences between obese and lean people, and restrained and unrestrained eaters, does not seem a very viable approach. It might be for a clinical disorder such as anorexia nervosa.

Zusammenfassung (Redaktion): In diesem Beitrag wird gezeigt, wie das Verhalten der Verbraucher bei der Auswahl von Lebensmitteln auf indirekte Weise erfasst werden sollte. Dies Verfahren ist insofern indirekt, als der Projektleiter den jeweiligen Probanden nicht direkt danach befragt, welche Lebensmittel er bevorzugen würde, sondern dies aus dessen Verhalten ableitet. Grundsätzlich wurden dabei das „affective priming paradigm“ und der „Implicit Association Test“ eingesetzt. Die relevanten Prozesse er- folgen bei diesen beiden Paradigmen relativ automatisch; einer ihrer Vorteile ist es, dass die Reaktionen der Probanden weniger durch gesellschaftlich wünschenswerte Tendenzen beeinflusst werden und sich nicht durch eine etwaige Selbsterkenntnis der Probanden begründen lassen. Es werden Untersuchungen vorgestellt, die sich generell mit den mit Lebensmitteln verbundenen Assoziationen befassen und im Besonderen mit denen von Magersüchtigen, Übergewichtigen und Personen, die sich bei der Nahrungsaufnahme bewusst beschränken. Verschiedene Studien scheinen zu suggerieren, dass mit diesen Paradigmen die Vorliebe für bestimmte Lebensmittel bzw. ihre Ablehnung ermittelt werden kann. In den meisten Studien unterschieden sich die Präferenzen für bestimmte Lebensmittel nicht bei übergewichtigen und schlanken Personen oder bei Personen, die sich bei der Nahrungsaufnahme bewusst beschränkten, und solchen, die sich nicht an solche Regeln hielten. Möglicherweise gibt es entweder keine gruppenspezifischen Unterschiede bei den automatisch mit Lebensmitteln verbundenen Assoziationen oder aber die angewandten indirekten Messverfahren sind nicht sensitiv genug, um tatsächlich bestehende Unterschiede aufspüren zu können. Interessanterweise konnte nachgewiesen werden, dass bei Magersüchtigen das Gespür für die Schmackhaftigkeit von Lebensmitteln weniger ausgeprägt ist. Von Interesse ist auch, dass das augenblickliche, auf ein Lebensmittel bezogene Umfeld Einfluss haben kann auf die automatischen, mit diesem Lebensmittel verbundenen Assoziationen. Es zeigte sich, dass die indirekten Verfahren derzeit nicht geeignet scheinen, um Unterschiede zwischen den Personengruppen mit verschiedenen Eßgewohnheiten erklären zu können. Sie mögen aber hinreichen für die Analyse klinischer Erscheinungsbilder wie zum Beispiel der Magersucht.

\section{Introduction: The value of indirect measures for assessing food preferences in abnormal eating}

Imagine a nice piece of Belgian chocolate! What is your first association? It will probably be that it is tasty. Research has shown 
that a liking for the sensory aspects of food is the most important factor determining food choice (Eertmans et al., 2001), which suggests that people's first association with food is likely based on the palatability of the food. Now think of an obese woman. What would her first association with that nice piece of chocolate be? Probably her first association is 'tasty' too, and it may be stronger than that of a lean person. Research suggests that food palatability is more important for obese people than for lean people (Nisbett, 1968; Pliner et al., 1990; Spiegel et al., 1989), and that the obese have a specific preference for high-fat foods (e. g. Mela and Sacchetti, 1991; Rissanen et al., 2002). Quite the opposite might be true for an anorexia nervosa patient. What would her first association be when she imagines that piece of chocolate? As Pinel et al. (2000) suggest, palatability may be relatively unimportant for anorexia nervosa patients, for whom food may have lost its positive incentive value. The main question that will be addressed in this paper is whether an increased 'pleasure of food' at an early stage of cognitive processing is related to overeating and obesity, and whether a decreased 'pleasure of food' at an early stage of cognitive processing is related to undereating, anorexia nervosa.

\section{Research methodology}

An obvious approach to address the central question whether overeating is associated with an increased pleasure from food, and undereating with a decreased pleasure from food, would be to simply ask people what foods they like and how important the palatability of food is to them. However, it has become common knowledge for psychology researchers that self-reports can sometimes be quite unreliable. An answer on a questionnaire is influenced by the wording of the question, the context, the order, and - perhaps most importantly - socially desirable response tendencies (Schwarz, 1999; Schwarz and Oyserman, 2001). Moreover, answers on a self-report measure rely on participants' introspection. Socially desirable response tendencies can surely be expected to play a role in research into food evaluations. For example, because in our society the beauty ideal is to be very slim, and obese people are stigmatized (Puhl and Brownell, 2003; Teachman and Brownell, 2001), it might be increasingly difficult to admit a liking or much consumption of high-fat palatable foods with increasing body weight (Heitmann et al., 2000).

To avoid the drawbacks of direct measures like questionnaires various indirect measures (Fazio and Olson, 2003) have been used to study food associations in abnormal eaters (e.g. obese people, anorexia nervosa patients). An indirect measure is indirect in the sense that the researcher does not directly ask the participant how he evaluates a certain object (e.g. a certain food), but instead bases it on another behavior (e.g. task performance in a computerized response latency paradigm). Moreover, these studies about food associations aim at assessing relatively spontaneous responses. In the paradigms that were used, the process of responding may be characterized as relatively automatic. Depending on the specific paradigm, the assessed processes can be automatic in the sense that they are rather effortless, not under voluntary control, not dependent on the participant's explicit intention to evaluate the food, and in the sense that the participant may be unaware of what the researcher is assessing. These functional properties are likely to reduce the effects of socially desirable response tendencies.

Mainly two paradigms have been used in the study of automatic food associations: the Implicit Association Test (Greenwald et al., 1998), and the affective priming paradigm (Fazio et al., 1986). Both paradigms are computerized tasks, in which participants have to respond as fast as possible to a series of (word) stimuli by pressing a button. Dependent measures are the average response latency and percentage of errors. The methodologies of the two paradigms will be briefly described here.

\subsection{Implicit Association Test}

Greenwald et al. (1998) developed the Implicit Association Test (IAT) as an indirect measure of attitudes. In the IAT, word stimuli are presented one at a time in the centre of a computer screen. Participants' task is to categorize each stimulus as quickly as possible according to a target-concept dimension (e.g., high-fat vs. low-fat foods; example stimuli: chocolate, strawberries) or an attribute dimension (positive vs. negative; example stimuli: holidays, disaster), while avoiding too many mistakes. Participants respond by means of a button press (e.g., press left button for high-fat foods and general positive words and right button for low-fat foods and general negative words). Foods have to be evaluated on the basis of the fat-content, whereas general positive and negative stimuli have to be evaluated based on their affective value. The IAT consists of five steps. The two crucial steps are the third and the fifth. In the third step, the initial combination block, high-fat and low-fat food words and positive and negative stimuli are presented randomly, while alternating stimuli from the target-concept-categories and stimuli from the attribute-categories (e.g., left=high-fat/positive; right = low-fat/negative). So, one target-concept-category and one attribute-category share a response key, while the other target-concept-category and other attribute-category share the other response key. The fifth step is the reversed combination block, and works the same as the third step, but now the key-assignment for the target-concept dimension is reversed (e.g., left = low-fat/positive, right = high-fat/negative). The IAT effect is calculated as the difference in average response latency and percentage of errors between steps 3 and 5. The logic behind the IAT is that it is easier to respond to two categories of stimuli with one button when these categories are associated than when they are not associated (high-fat/negative + low-fat/ positive in step 5 vs. high-fat/positive + low-fat/negative in step $3)$. So, in this example, if people are faster in step 5 than in step 3 , they prefer low-fat foods over high-fat foods, when assessed by the IAT.

\subsection{Affective priming paradigm}

In the affective priming paradigm (Fazio et al., 1986; Klauer and Musch, 2003), two stimuli are presented in quick succession, a prime word followed by a target word. No response is required to the prime, which is simply displayed and replaced by the target. Participants have to respond to the target by evaluating it as being positive or negative. The dependent variable is the positive/negative key-press latency in response to the target. 
The focus of the priming paradigm is on the extent to which the presentation of the prime influences the response to the target. Typically, affectively congruent prime-target pairs (e.g., "love" - "happy") lead to shorter response latencies to the target word than do affectively incongruent prime-target pairs (e.g., "love" -“awful") (Fazio et al., 1986; Hermans et al., 2001). The critical idea is that the pattern of response latencies as a function of affect match between prime and target indicates how people evaluate the prime on a fairly automatic level. Applied to the palatability of food, if people respond faster on congruent trials ('palatable - positive' and 'unpalatable - negative') than on incongruent trials ('palatable - negative' and 'unpalatable - positive'), it can be inferred that they like palatable foods more than unpalatable foods.

\section{Can indirect measures be used to assess food preferences?}

Maison et al. (2001) used the IAT to measure consumer attitudes towards juices and sodas. On the IAT and on direct measures (questionnaires) participants preferred juices over of sodas. Moreover, the attitude assessed by the IAT correlated with selfreported behavior, behavioral intention, self-reported liking, and subjective beliefs. Maison et al. (2001) concluded that the IAT did quite well, in that it correlated with behavior in normal participants. The drawback, however, is that this behavior was assessed by a self-report.

Karpinski and Hilton (2001) assessed actual choice behavior, and used the IAT to measure consumer attitudes toward candy bars and apples. Participants in this experiment completed an IAT with apple vs. candy bar as the target-concept dimension, some direct preference measures (questionnaires), and at the end of the experiment chose between an apple and a candy bar (behavioral measure). The IAT results revealed a preference for apples over candy bars. However, the IAT did not correlate with the direct preference measures or the behavioral choice test. So, the IAT could not predict food choice behavior. The direct measures on the other hand did correlate with the behavioral choice test. Note that this does not mean that the IAT cannot predict behavior in other domains (Poehlman et al., 2005). Karpinsky and Hilton (2001) propose that the IAT does not really measure personal preferences but culture based associations. The level of exposure to certain associations in your culture will determine the IAT effect. In Western culture the idea is widespread that apples are good for your, apples are hardly ever associated with negative. Candy bars on the other hand are palatable, but have the drawback that they are fattening and bad for your health. This pattern of cultural associations may very well explain Karpinsky and Hilton's IAT results. Of course this is problematic if one is interested in personal attitudes.

Besides replicating the results of Karpinsky and Hilton (2001), Olson and Fazio (2004) introduced a personalized version of the IAT. The most important adjustment to the IAT procedure is that they changed the attribute labels from 'positive' and 'negative' to 'I like' and 'I dislike'. Results of this personalized IAT suggest that people like candy bars as much as apples. The personalized IAT results correlated significantly with all direct preference measures and with behavior. Olson and Fazio (2004) take this as evidence that their personalized version of the IAT is less contaminated by extrapersonal associations.

Perugini (2005) extended Karpinsky and Hilton's study (2001) by including an additional - self reported - behavioral measure and by examining the general categories of snacks vs. fruits instead of candy bars vs. apples. In line with Karpinsky and Hilton (2001) and with Olson and Fazio (2004) Perugini's IAT results (2005) are indicative of a preference for fruits over snacks. However, Perugini did find a correlation between the IAT and the behavioral choice task. The self-reported behavioral measure correlated with the direct questionnaire measure of preferences. The IAT did not correlate with the direct questionnaire measure. So Perugini's correlational results do not correspond with the results of Karpinsky and Hilton (2001) and of Olson and Fazio (2004). Perugini ascribes this to methodological differences.

Taken together, the IATs that were used likely assessed food preferences based on health concerns: juice was preferred over soda, apples over candy bars, and fruits over snacks. In two studies the IAT correlated with a (self-reported) behavioral measure, whereas it did not in two other studies. This pattern of results may be explained by the possibility that the IAT measures cultural associations instead of personal evaluations (Karpinsky and Hilton, 2001; Olson and Fazio, 2004). The issue of whether the IAT is contaminated by cultural associations is still a matter of much debate, and may depend on the exact theme (e.g. black-white, juice-soda, insects-flowers, etc.) of the IAT (Han et al., 2006; Olson and Fazio, 2004). To avoid this problem and other drawbacks of the IAT (De Houwer, 2002), some researchers tried to assess food preference in another paradigm, the affective priming paradigm.

Spruyt et al. (2003) extended the study of Karpinsky and Hilton (2001) and directly compared the ability of the IAT and two variants of the affective priming paradigm to predict food choice behavior (apple vs. candy). Again, the IAT could not predict food choice behavior, whereas one of the variants of the affective priming paradigm could. This suggests that the affective priming paradigm may be less influenced by cultural associations and might be better at assessing personal evaluations (Olson and Fazio, 2004). Additionally, the affective priming paradigm can overcome another of the drawbacks of the IAT. That is, the IAT mainly assesses an attitude toward the category (e. g. fruits vs. snacks) and not so much toward the individual exemplars (e. g. chocolate, strawberry; De Houwer, 2001; Mitchell et al., 2003). The name of the category (label) may elicit different attitudes than the separate exemplars of the category. High-fat foods are generally seen as negative, whereas chocolate can be seen as positive (palatable) when it is not categorized as a highfat food. So, the labels of the categories in the IAT strongly influence the results. The affective priming paradigm does not suffer from this problem, because participants are not required to categorize the stimuli on a pre-defined dimension.

With exactly this idea in mind - that the affective priming paradigm might be better suited to assess food preferences - Lamote et al. (2004) explored the value of the affective priming paradigm as an indirect measure of food attitudes. Their results indicate that the affective priming paradigm is success- 
ful at assessing food preferences for both food items with an extreme affective meaning and food items with a moderate affective meaning. In other words, the paradigm works for both strongly liked and disliked foods, and for moderately liked and disliked foods. Though - as Lamote et al. (2004) mention as well - this is only a first study exploring the usefulness of the affective priming paradigm for studying food preferences, it seems to be well-suited.

Recently Hermans et al. (2005) took these observations one step further, and tested whether the affective priming paradigm would also be sensitive to previously neutral foods that acquired their affective meaning through a conditioning procedure. In the acquisition phase, pictures of yoghurts were paired with a positive odor, a negative odor, or a neutral odor. In the affective priming task these yoghurts functioned as the primes. Targets were general positive and negative words. Results showed that participants were faster on the congruent trials (positive yoghurt - positive words/negative yoghurt - negative words) than on the incongruent trials (positive yoghurt - negative words/negative yoghurt-positive words). It can thus be inferred that the affective priming paradigm can pick up the recently acquired valence of the yoghurts. This study contributes to the evidence that the affective priming paradigm seems well-suited to assess food preference, and suggests that the affective priming paradigm is sensitive to personal attitudes.

In sum, the studies described above suggest that both indirect measures - the IAT and the affective priming paradigm - are of value for the assessment of food preferences. However, the IAT procedure has certain drawbacks, and only one of the priming studies (Spruyt et al., 2003) included a behavioral measure of food preference. More research needs to be conducted before a more definite conclusion can be reached concerning the predictive validity of these indirect measures.

\section{Can indirect measures assess differences in food preferences and associations among obese people, restrained eaters, and anorexia nervosa patients?}

Based on research that suggests that palatability is more important for the food consumption of obese people than for the food consumption of lean controls (Nisbett, 1968; Pliner et al., 1990; Spiegel et al., 1989), and on studies that suggest that obese people may specifically like high-fat palatable foods (e. g. Drewnowski et al., 1992; Gerding and Weinstein, 1992; Rissanen et al., 2002), Roefs and Jansen (2002) hypothesized that obese people would show an increased liking of high-fat palatable foods when assessed in the IAT, compared to lean controls. They used an IAT with high-fat vs. low-fat foods as the target-concept categories. Results suggest exactly the opposite, in that all participants preferred low-fat foods over high-fat foods on a relatively automatic level, and this effect was most pronounced for the obese people. Though surprising at first, the finding fits well with findings from Maison et al. (2001) in which an IAT with low calorie foods vs. high calorie foods as the target-concept dimension was used. Maison et al. (2001) found on average a preference for low calorie foods over high calorie foods. Moreover, this preference was positively related with dieting activity: the more dieting activity, the stronger the preference for low calorie over high calorie foods was. In the study of Roefs and Jansen (2002) dieting activity was also correlated with the preference for low-fat over high-fat foods.

Similar to the IAT studies that were discussed in the previous section (Karpinski and Hilton, 2001; Maison et al., 2001; Perugini, 2005), again it seems that the IAT results were based on health concerns: a preference for low-fat over high-fat foods and a preference for low calorie foods over high calorie foods. These findings can be explained by the fact that the IAT effect is largely driven by the category labels (De Houwer, 2001; Mitchell et al., 2003). It may not be too surprising that (especially obese) people have negative associations with the high fat content of foods, though they may obviously like the taste of, for example, chocolate. So categorizing foods as high-fat and low-fat might have biased the relatively automatic evaluation of food, because participants were constantly evaluating the fat content, which made fat content salient. This can explain the found preference for low-fat foods over high-fat foods. Moreover, as argued before (Karpinsky and Hilton, 2001; Olson and Fazio, 2004), these category labels may elicit cultural associations. In our culture, low-fat foods are generally more consistently portrayed as good in comparison to high-fat foods.

To overcome the disadvantages of category labels and cultural associations in the IAT, Craeynest et al. (2005) used a modified version of the IAT, the Extrinsic Affective Simon Task (EAST) (De Houwer, 2003), and hypothesized a specific liking for unhealthy foods in obese children. It is beyond the scope of the present article to explain this paradigm in detail, but it is important to know that the advantage of this paradigm is that no category labels need to be used. Contrary to their hypothesis, Craeynest et al. (2005) did not find a preference for unhealthy (mainly high-fat) foods over healthy (low-fat) foods specifically for obese children. Instead, obese children showed a positive association with both types of foods, whereas normal weight children showed a neutral response towards both types of food. Craeynest et al. (2005) suggest that this may mean that obese children simply like eating, not specifically unhealthy foods. In contrast with Roefs and Jansen (2002) obese children's associations with unhealthy foods were positive. This difference might be explained by the fact that no categorization (high-fat vs. low-fat) was required in the EAST whereas it was in the IAT. Because no categorization was required, participants were not constantly reminded of the fat content of the foods. So associations with foods were assessed in a less biased way.

With the same goal in mind - avoiding label-based categorization - Roefs et al. (2005a) used the affective priming paradigm and the EAST to assess food likes and dislikes in restrained and unrestrained eaters. A large proportion of dieters can be classified as restrained eaters. Heatherton et al. (1988, p. 19) define restrained eaters, as selected by the Restraint Scale (Herman and Polivy, 1980), as dieters who "exhibit periods of restraint punctuated by episodes of disinhibited overeating." In other words, restrained eaters are people who want to lose weight, but regularly fail and indulge in exactly those high-fat palatable foods that they normally consider "forbidden" (Herman and Polivy, 1980 and 2004). Restrained eating is hypothesized to be associated with (high-fat) palatable foods being 
extra desirable (Gendall and Joyce, 2001; Stice, 2002). So, Roefs et al. (2005a) hypothesized that restrained eaters would show a stronger liking of high-fat palatable foods than unrestrained eaters would. Results showed that both paradigms - the EAST and the affective priming paradigm - were successful in uncovering food likes and dislikes. Both paradigms showed that participants preferred palatable foods over unpalatable foods. However, contrary to the hypothesis, food likes were not influenced by participant's restraint status. No group differences could be detected.

In a related study, Roefs et al. (2005b) compared a group of obese participants to a group of lean participants, again testing the hypothesis that obese people would show more sensitivity to the palatability of (high-fat) palatable foods, using the affective priming paradigm. Results suggest that the priming effect was based on health concerns, in that participants showed a preference for low-fat palatable foods over high-fat palatable foods, independent of weight status. So again no increased liking for high-fat palatable foods in obese participants could be detected. These findings actually fit well with the results of Werrij et al. (2005). Using a semantic priming paradigm (Neely, 1991), Werrij et al. (2005) found that the presentation of palatable food words facilitated the accessibility of restraint related concepts, independent of weight status (obese vs. lean). For example, the word 'chocolate' was associated with 'diet'. The results of Roefs et al. (2005b) were a bit surprising because the affective priming paradigm can be considered neutral, in that participants were not required to sort the prime stimuli into predefined categories (cf. IAT: high-fat vs. low-fat). In the study of Roefs et al. (2005a) the priming effect was based on palatability, and the affective priming paradigm was successful at uncovering food likes and dislikes. Possibly, the context in which the experiment (Roefs et al., 2005b) took place, namely a hospital, an environment in which health is obviously salient, played a role. As Blair (2002) reviews, very subtle context manipulations can influence the outcome of indirect measures. In the IAT, health concerns were made salient by the category labels (high-fat vs. low-fat), whereas in this experiment (Roefs et al., 2005b) health might have been made salient by the hospital environment.

Roefs et al. (2006) specifically addressed the possibility that the current environment or situation influences the automatic associations as assessed by the affective priming paradigm. In the Western world, palatable high-fat foods are abundant, and on almost every street corner one is reminded of some kind of nice food. It is likely that the environment exerts its influence on relatively automatic evaluations by shaping the way food is conceptualized (Mitchell et al., 2003). Chocolate for example can either be conceptualized as a very palatable food, or as an unhealthy fattening food. The environment may trigger how you conceptualize the food on that moment, by making certain associations more available than others (Smith et al., 1996). The goal of Experiment 1 of Roefs et al. (2006) was to investigate how a manipulation of attention focus would influence relatively automatic associations with food. In this experiment, the focus of attention was manipulated by having participants read a script and having then answer some questions. Half of the participants were asked to imagine that they were a restaurant owner about to prepare a fancy dinner. The other half of the participants were given information about healthy eating. After reading the scripts and answering the questions, participants performed the same affective priming task as in the study of Roefs et al. (2005b). The manipulations proved to be effective in influencing the affective associations, in that the priming effect for people in the restaurant condition was based on palatability, whereas it was based on health concerns for people in the healthy food condition. Weight-status (obese vs. lean control) did not influence the priming results.

The studies described in this section so far were largely unsuccessful in showing that obese people or restrained eaters would be characterized by a stronger liking of high-fat palatable foods. What about the opposite, a relatively decreased sensitivity to the palatability of foods? To study this possibility, Roefs et al. (2005b) compared a group of anorexia nervosa patients to a control group of lean unrestrained eaters in the affective priming paradigm. Based on related but different theoretical perspectives, both Pinel et al. (2000) and Jansen (1998 and 2001) propose that food may have lost its incentive value for anorexia nervosa patients. Support for these ideas was found in both self-report studies and psychophysiological studies with either anorexia nervosa patients or fasting participants (e. g. Lappalainen et al., 1990; Legoff et al., 1988). Moreover, a different line of research suggests that anorexia nervosa patients may be more anhedonic than normal controls (Davis and Woodside, 2002). In other words, they might have a deficit in experiencing pleasure. Plausibly, this suggests that they do not value the palatability of food as much as normal controls.

Based on these theories and previous research, Roefs et al. (2005b) tested the hypothesis that anorexia nervosa patients would show a reduced sensitivity to the palatability of food at a relatively automatic level. The results of this experiment confirmed the hypothesis, in that the lean control group showed a palatability priming effect, whereas this effect was absent in the anorexia nervosa group. These results showed that anorexia nervosa patients did not automatically categorize foods as either palatable or unpalatable, and suggest that the palatability of food is no longer important for anorexia nervosa patients, which in turn might make food restriction easier. Note, however, that the anorexia group responded relatively slowly in comparison to the lean control group, which might have left too much time for controlled processing for an affective priming effect to occur (see Hermans et al., 2002). Exactly why the anorexia patients responded so slowly is unclear. This might reflect the fact that food is a source of worries for them and therefore captures their attention relatively long (the emotional Stroop effect) (Williams et al., 1996), or they might simply be cognitively slower (Green et al., 1996).

\section{Conclusions and future research}

No stable differences in relatively automatic food evaluations between overeaters (obese people and restrained eaters) and normal controls were found in the expected direction specifically for high-fat palatable foods. Only Craeynest et al. (2005) found a difference between obese and lean children in the expected direction. However, this effect was not specific for 
the unhealthy (mainly high-fat) foods. Of course, the theory might be wrong, but it could also be that the employed indirect measures are not sensitive enough to pick up the alleged group differences.

On the other hand, the results of Roefs et al. (2005b) suggests that anorexia nervosa patients are less sensitive to the palatability of food than lean unrestrained eaters. So, this time the affective priming paradigm did pick up a group difference in food associations. A possible explanation is that anorexia nervosa is a real clinical disorder (APA, 1994), and is characterized by cognitive biases (Dobson and Dozois, 2004). Measures like affective priming might be more sensitive to cognitive biases than to differential liking of food.

The experiment with anorexia nervosa patients took place in a relatively neutral environment (university) and used a relatively "bias-free" paradigm, as was the case in the studies by Roefs et al. (2005a) in which restrained and unrestrained eaters were compared. All participants in the studies of Roefs et al. (2005a) showed a preference for palatable foods over unpalatable, which was not modified by restraint-status or fat content. So, in a relatively neutral environment and paradigm, anorexia nervosa patients were the only group not showing a relative preference for palatable foods at an early stage of cognitive processing. Note however that the anorexia nervosa patients responded relatively slowly in comparison to the lean controls.

Environment actually seems to play a very important role in relatively automatic food evaluations. The IAT studies (Maison et al., 2001; Roefs and Jansen, 2002) unintentionally focused attention on health by having participants categorize foods as either high-fat (high-caloric) or low-fat (low-caloric). The study with obese participants (Roefs et al., 2005b) took place in a hospital, which may also have emphasized health aspects. Roefs et al. (2006) showed that an intentional manipulation of the salience of fat content and palatability of food was successful in influencing the affective priming effect. If the manipulation focused on palatability aspects, a relatively automatic evaluation of the foods was based on palatability. If the manipulation focused on health aspects, a relatively automatic evaluation was based on the healthiness of the foods. This finding is important because our environment is characterized by an abundance of high-fat palatable foods (Hill and Peters, 1998) in increasingly large portions (Nielsen and Popkin, 2003). Everywhere around us we are reminded of palatable high-fat foods, whereas health related cues obviously exist but may be less abundant. This may lead to a categorization of food into palatable and unpalatable, and thereby to relatively automatic evaluations based on palatability. If so, people may not be reminded of the health consequences of food often enough. Whether this leads to higher consumption of (high-fat) palatable foods remains an issue for future research. Interestingly, Mann and Ward (2004) found that high-restrained eaters ate more in a situation in which the food itself was made salient than when their diet was made salient, when under high cognitive load.

Concluding, the affective priming paradigm was successful at distinguishing between a clinical group (anorexia nervosa patients) and healthy lean controls. However for now, the use of indirect measures in explaining differences between obese and lean people, and restrained and unrestrained eaters, does not seem a very viable approach. The field of indirect measures is a very active field at the moment. So methods may be improved in the future. But from the research conducted so far, it seems that to explain differences in weight between overeaters and normal controls, one should look elsewhere.

\section{References}

American Psychiatric Association (1994) Diagnostic and Statistical Manual of Mental Disorders ( $4^{\text {th }}$ ed.). Washington, DC: Author.

Blair, I. V. (2002) The malleability of automatic stereotypes and prejudice. Personal Social Psychol Rev 6:242-261.

Craeynest, M., Crombez, G., De Houwer, J., Deforche, B., Tanghe, A. and De Bourdeaudhuij, I. (2005) Explicit and implicit attitudes towards food and physical activity in childhood obesity. Behav Res Therapy 43:1111-1120.

Davis, C., and Woodside, D. B. (2002) Sensitivity to the rewarding effects of food and exercise in the eating disorders. Comprehensive Psychiatry 43:189-194.

De Houwer, J. (2001) A structural and process analysis of the Implicit Association Test. J Exp Social Psychol 37:443-451.

De Houwer, J. (2002). The implicit association test as a tool for studying dysfunctional associations in psychopathology: strengths and limitations. J Behav Therapy Exp Psychiatry 33:115-133.

De Houwer, J. (2003) The extrinsic affective Simon task. Exp Psychol 50:77-85.

Dobson, K. S. and Dozois, D. J. A. (2004) Attentional biases in eating disorders: A meta-analytic review of Stroop performance. Clin Psychol Rev 23:1001-1022.

Drewnowski, A., Kurth, C., Holden Wiltse, J. and Saari, J. (1992) Food preferences in human obesity: Carbohydrates versus fats. Appetite 18:207-221.

Eertmans, A., Baeyens, F. and Van den Bergh, O. (2001) Food likes and their relative importance in human eating behavior: review and preliminary suggestions for health promotion. Health Education Res 16:443-456.

Fazio, R. H. and Olson, J. M. (2003) Implicit measures in social cognition research: Their meaning and use. Ann Rev Psychol 54:297-327.

Fazio, R. H., Sanbonmatsu, D. M., Powell, M. C. and Kardes, F. R. (1986) On the automatic activation of attitudes. J Personality Social Psychol 50:229-238.

Gendall, K. A. and Joyce, P. R. (2001) Characteristics of food cravers who binge eat. In: Hetherington, M. M. (ed.) Food cravings and addiction. London: Leatherhead Publishing, pp. 567-583.

Gerding, A. L. and Weinstein, L. (1992) Taste ratings of obese people, and taste preferences based on geographical location. Bull Psychonomic Soc 30:509-510.

Green, M. W., Elliman, N. A., Wakeling, A. and Rogers, P. J. (1996) Cognitive functioning, weight change and therapy in anorexia nervosa. J Psychiatric Res 30:401-410.

Greenwald, A. G., McGhee, D. E. and Schwartz, J. L. K. (1998) Measuring individual differences in implicit cognition: The implicit association test. J Personality Social Psychol 74:1464-1480.

Han, H. A., Olson, M. A. and Fazio, R. H. (2006) The influence of experimentally-created extrapersonal associations on the implicit association test. J Exp Social Psychol 42:259-272.

Heatherton, T. F., Herman, C. P., Polivy, J., King, G. A. and McGree, S. T. (1988) The (mis)measurement of restraint: An analysis of conceptual and psychometric issues. J Abnormal Psychol 97:19-28.

Heitmann, B., Lissner, L. and Osler, M. (2000) Do we eat less fat, or just report so? Internat J Obesity 24:435-442.

Herman, C. P. and Polivy, J. (1980). Restrained eating. In: Stunkard, A. J. (ed.) Obesity. Philadephia: Saunders, pp. 208-225.

Herman, C. P. and Polivy, J. (2004) The self-regulation of eating: Theoretical and practical problems. In: Baumeister, R. F. and Vohs, K. D. (eds.) Handbook of Self-Regulation Research. New York: Guilford Press, pp. 492-508. 
Hermans, D., Baeyens, F., Lamote, S., Spruyt, A. and Eelen, P. (2005) Affective priming as an indirect measure of food preferences acquired through odor conditioning. Exp Psychol 52:180-186.

Hermans, D., De Houwer, J. and Eelen, P. (2001) A time course analysis of the affective priming effect. Cognition and Emotion 15:143-165.

Hermans, D., Smeesters, D., De Houwer, J. and Eelen, P. (2002) Affective priming for associatively unrelated primes and targets. Psychologica Belgica 42:191-212.

Hill, J. O. and Peters, J. C. (1998) Environmental contributions to the obesity epidemic. Science 280:1371-1374.

Jansen, A. (1998) A learning model of binge eating: Cue reactivity and cue exposure. Behav Res Therapy 36:257-272.

Jansen, A. (2001) Craving and binge eating. In: Hetherington, M. M. (ed.) Food cravings and addiction . Surrey: Leatherhead Publishing LFRA Limited, pp. 549-565.

Karpinski, A. and Hilton, J. L. (2001) Attitudes and the Implicit Association Test. J Personality Social Psychol 81:774-788.

Klauer, K. C. and Musch, J. (2003). Affective priming: Findings and theories. In: Musch, J. and Klauer, K. C. (eds.) The psychology of evaluation. Mahway, New Jersey: Lawrence Erlbaum Associates, Publishers, pp. 7-49.

Lamote, S., Hermans, D., Baeyens, F. and Eelen, P. (2004) An exploration of affective priming as an indirect measure of food attitudes. Appetite 42:279-286.

Lappalainen, R., Sjödén, P., Hursti, T. and Vesa, V. (1990) Hunger/craving responses and reactivity to food stimuli during fasting and dieting. Internat J Obesity 14:679-688.

Le Goff, D. B., Leichner, P. and Spigelman, M. N. (1988) Salivary response to olfactory food stimuli in anorexics and bulimics. Appetite 11:1525.

Maison, D., Greenwald, A. G. and Bruin, R. (2001) The Implicit Association Test as a measure of implicit consumer attitudes. Polish Psychological Bull 32:61-69.

Mann, T. and Ward, A. (2004) To eat or not to eat: Implications of the attentional myopia model for restrained eaters. J Abnormal Psychol 113:90-98.

Mela, D. J. and Sacchetti, D. A. (1991) Sensory preferences for fats: relationships with diet and body composition. Amer J Clin Nutrition 53:908-915

Mitchell, J. P., Nosek, B. A. and Banaji, M. R. (2003) Contextual variations in implicit evaluation. J Exp Psychol 132:455-469.

Neely, J. H. (1991) Semantic priming effects in visual word recognition: A selective review of current findings and theories. In: Besner, D. and Humphreys, G. W. (eds.) Basic processes in reading: Visual word recognition. Hillsdale, New Jersey: Lawrence Erlbaum Associates, pp. 264-337.

Nielsen, S. J. and Popkin, B. M. (2003) Patterns and trends in food portion sizes, 1977-1998. JAMA 289:450-453.

Nisbett, R.E. (1968) Taste, deprivation, and weight determinants of eating behavior. J Personality Social Psychol 10:107-116.

Olson, M. A. and Fazio, R. H. (2004) Reducing the influence of extrapersonal associations on the implicit association test: Personalizing the IAT. J Personality Social Psychol 86:653-667.

Perugini, M. (2005) Predictive models of implicit and explicit attitudes. British J Social Psychol 44:29-45.

Pinel, J. P. J., Assanand, S. and Lehman, D. R. (2000) Hunger, eating, and ill health. Amer Psychologist 55:1105-1116.
Pliner, P., Herman, C. P. and Polivy, J. (1990) Palatability as a determinant of eating: finickiness as a function of taste, hunger, and the prospect of good food. In: Capaldi, E. D. and Powley, T. L. (eds.) Taste, experience, and feeding. Washington, DC, USA: Amer Psychol Assoc, pp. 210-225

Poehlman, T. A., Uhlmann, E., Greenwald, A. G. and Banaji, M. R. (2005) Understanding and using the Implicit Association Test: III. Metaanalysis of predictive validity. Yale University: New Haven, CT, unpublished.

Puhl, R. and Brownell, K. D. (2003) Ways of coping with obesity stigma: Review and conceptual analysis. Eating Behaviors 4:53-78.

Rissanen, A., Hakala, P., Lissner, L., Mattlar, C. E., Koskenvuo, M. and Ronnemaa, T. (2002) Acquired preference especially for dietary fat and obesity: a study of weight-discordant monozygotic twin pairs. Internat J Obesity 26:973-977.

Roefs, A., Herman, C. P., MacLeod, C. M., Smulders, F. T. Y. and Jansen, A. (2005a) At first sight: how do restrained eaters respond to high-fat palatable foods? Appetite 44:103-114.

Roefs, A. and Jansen, A. (2002) Implicit and explicit attitudes toward high-fat foods in obesity. J Abnormal Psychol 111:517-521.

Roefs, A., Quaedackers, L., Werrij, M. Q., Wolters, G., Havermans, R., Nederkoorn, C., Van Breukelen, G. and Jansen, A. (2006) The environment influences whether high-fat foods are associated with palatable or with unhealthy. Behav Res Therapy 44:715-736.

Roefs, A., Stapert, D., Isabella, L. A. S., Wolters, G., Wojciechowski, F. and Jansen, A. (2005b) Early associations with food in anorexia nervosa patients and obese people assessed in the affective priming paradigm. Eating Behaviours 6:151-163.

Schwarz, N. (1999) Self-reports: How the questions shape the answers. Amer Psychologist 54:93-105.

Schwarz, N. and Oyserman, D. (2001) Asking questions about behavior: Cognition, communication, and questionnaire construction. Amer J Evaluation 22:127-160.

Smith, E. R., Fazio, R. H. and Cejka, M. A. (1996) Accessible attitudes influence categorization of multiply categorizable objects. J Personality Social Psychol 71:888-898.

Spiegel, T. A., Shrager, E. E. and Stellar, E. (1989) Responses of lean and obese subjects to preloads, deprivation, and palatability. Appetite 13:45-69.

Spruyt, A., Hermans, D. an De Houwer, J. (2003) On the predictive validity of implicit attitude measures: the IAT and the affective priming paradigm compared. Paper presented at the Special Interest Meeting on the Use of Indirect Measures of Attitudes and Associations in Clinical and Health Psychology, Diksmuide, Belgium.

Stice, E. (2002) Risk and maintenance factors for eating pathology: A meta-analytic review. Psychol Bull 128:825-848.

Teachman, B. A. and Brownell, K. D. (2001) Implicite anti-fat bias among health professionals: Is anyone immune? Internat J Obesity 25:1525-1531.

Werrij, M. Q., Roefs, A., Janssen, I., Stapert, D., Wolters, G., Mulkens, S. et al. (2005) Early associations with palatable foods in obesity are not disinhibition related but restraint related. Maastricht University, The Netherlands, unpublished.

Williams, J. M. G., Mathews, A. and MacLeod, C. (1996) The emotional Stroop task and psychopathology. Psychol Bull 120:3-24. 